\title{
Synthesis
}

International Scientific Conference of IT and Business-Related Research

\section{SIMULACIJA ODNOSA SIMBOL - ŠUM I ENERGETSKE EFIKASNOSTI KORIŠĆENJEM ALGEBARSKIH RAČUNARSKIH ALATA: STUDIJA SLUČAJA OFDM PRIJEMNIKA}

\section{SIMULATION OF SYMBOL - ERROR RATIO AND ENERGY EFFICIENCY USING COMPUTER ALGEBRA TOOLS: A CASE STUDY OF OFDM RECEIVER}

\author{
Vladimir Mladenović ${ }^{1}$, Miroslav Lutovac ${ }^{2}$ \\ ${ }^{1}$ Univerzitet u Kragujevcu, Fakultet tehničkih nauka u Čačku, Svetog Save 65, Čačak, Srbija \\ ${ }^{2}$ Univerzitet Singidunum, Danijelova 32, Beograd, Srbija
}

\begin{abstract}
Apstrakt:
$\mathrm{U}$ ovom radu predstavljen je novi pristup originalne procedure za simulaciju OFDM prijemnika koje se zasniva na algebarskim računarskim alatima, simboličkoj obradi signala, i analizi podataka dobijenih softverskim alatima (Mathematica i SchematicSolver). Prikazan je način izračunavanja energetske efikasnosti za navedeni prijemnik. Ilustrovana je primena simboličkog procesiranja kod razvoja navedenog prijemnika koja zahteva korišćenje veoma sofisticiranih i složenih algoritama koji kombinuju ekspertizu u oblasti softverskog inženjerstva i obrade signala. Prikazan je način kako post procesiranje uspešno savladava neke probleme sa kojima se susreće tradicionalni numerički pristup upotrebom algebarskih računarskih sistema. Znanje ugrađeno u simboličke objekte je korišćeno je za simulaciju sistema OFDM, kao i za generisanje implementacije kod nekih kritičnih delova sistema.
\end{abstract}

\section{Ključne reči:}

algebarski računarski sistemi, Mathematica, OFDM, SchematicSolver, simboličko procesiranje, energetska efikasnost.

\section{UVOD}

Ortogonalno frekvencijsko multipleksiranje (eng. OFDM - Orthogonal Frequency Division Multiplexing) je digitalna tehnika prenosa sa više nosilaca koji prenose digitalno kodirane simbole preko podnosilaca kako bi se postigla stabilnost $\mathrm{u}$ odnosu na refleksije kod višestrukih radio kanala (Porrat, 2007; Nee \& Prasad, 2000). Spektri pojedinačnih podnosilaca se preklapaju i informacije se mogu u potpunosti rekonstruisati bez interference od drugih podnosilaca. Sa matematičke tačke gledišta ovo je posledica ortogonalnosti bazirane na Fourierovoj transformaciji. Ova tehnika je veoma upotrebljiva za profesionalnu upotrebu kod bežičnih komunikacionih sistema (Schulze \& Luders, 2005) U OFDM sistemu, koriste se algoritmi brze i inverzne brze Furierove trasformacije (eng. IFFT/FFT - Inverse Fast Fourier Transform/Fast Fourier Transform) za modulaciju i demodulaciju signala. Podaci se formiraju u vidu IFFT/ FFT čija dužina određuje otpornost sistema na grešaka izazvane prostiranjem signala kroz višestruke kanale. Sa druge strane, standard za zemaljski digitalni video prenos (eng. DVB-T Terrestrial Digital Video Broadcasting) bio je značajan predmet istraživanja u Evropi (DVB-T, 2013). Zemaljski mrežni operater može izabrati jedan od dva režima rada (Broadcast papers, 2003, Glover \& Grant, 2010): 2k mod - pogodan za pojedinačne predajnike i male jednofrekvencijske mreže sa ograničenim predajnim rastojanjem koji koristi 1705 nosilaca, i 8k mod - pogodne

\section{Abstract:}

This paper presents a new approach to the original procedure for simulation of OFDM receiver based on the algebraic computing tools, symbolic signal processing, and the analysis of data obtained by means of software tools (Mathematica and SchematicSolver). A method of calculating energy efficiency for the given receiver is shown. The use of symbolic processing in the development of the above-given receivers is illustrated requiring the use of very sophisticated and complex algorithms combining expertise in the field of software engineering and signal processing. The paper also shows how post-processing successfully manages some of the issues encountered by traditional numerical approach using algebraic computer systems. Knowledge base of symbolic objects is used to simulate the example of OFDM, as well as to generate implementation of some critical parts of the system.

\section{Key words:}

Computer algebra system, Mathematica, OFDM, SchematicSolver, symbolic processing, energy efficiency.

i za pojedinačne predajnike i jednofrekvencijske male i velike mreže koje koriste 6817 nosilaca. Obično, standardom su predviđene vrednosti transformacije dužine 2048, 4096 i 8196 (2k, $4 \mathrm{~K}$ i $8 \mathrm{~K}$ ) (Fischer, 2010). OFDM se uspešno koristi kod zemaljskog digitalnog video prenosa i pokazao da se jak kandidat za modulacionu tehniku budućih komunikacionih sistema. Ovaj rad se bavi koliko se dobro koristi OFDM DVB kada se informacije prenose kada je u kanalu prisutan aditivni beli Gausov šum (eng. AWGN - Additive White Gaussian Noise). Kreiran je i realizovan simulacioni model sa novim konceptom obrade i analize signala, i projektovanja pomoću SchematicSolver i Mathematica. OFDM signal je primljen na ulazu OFDM prijemnika na isti način kao u (Acosta, 2008). Mnogi istraživački centri u svetu imaju specijalizovane timove koji rade na optimizaciji OFDM za bezbroj aplikacija, kao što su na Georgia Institute of Technology - Smart Antenna Research Laboratory (SARL), deo Georgia Center za napredne telekomunikacije tehnologiju (eng. GCATT - Georgia Center for Advanced Telecommunications Technology). U radu (Acosta, 2008) je dat Matlab (2005) kôd koji simulira osnovnu obradu uključenu u generisanje OFDM signala u fizičkom kanalu sa detaljnim opisom svakog od koraka simulacije. Zanimljivo je da su neki signali Matlab simulacije i direktne simulacije bili slični, ali ne i identični za iste ulazne podatke. Štaviše, autor zaključuje da je očekivao da imaju različite rezultate za iste ulazne podatke jer su koristili različite FFT-IFFT blokove. Upotreba algebarskih računarskih sistema 
(eng. CAS - Computer Algebra Systems) i simboličke obrade može pomoći da se steknu uvid u to kako složen sistem funkcioniše. Termin post procesiranje (eng. Post Processing) se koristi u obradi signala za korišćenje dodatnog softvera na takav način da pronađe razumljive rezultate koji ne mogu biti izvedeni prethodnim softverima. Svrha ovog rada je da pruži CAS kôd koji simulira osnovnu obradu uključenu u generisanje OFDM signala u fizičkom kanalu i pronalazi razloge za neočekivane razlike u dobijenim signalima pomoću numeričkih simulacija. Izračunavanja se izvode korišćenjem Mathematica (Wolfram, 2003) i aplikativnim paketom SchematicSolver (Lutovac \& Tosic, 2010). Simulacioni model je isti kao što je prikazano u radu (Acosta, 2008). Više detalja o tome kako se CAS može koristiti u teoriji upravljanja, telekomunikacijama, numeričkih nelinearnih optimizacija i pri dizajnu digitalnih filtera može se naći u radovima (Lutovac \& Tosic, 2006; Tosic \& Lutovac, 2007; Lutovac \& Mladenovic, 2007; Lutovac et al., 2010, Lutovac et al., 2001). Kako bi procenio učinak, za nivo SNR, prijemni signal je demodulisan i dobijeni podaci su upoređeni sa originalnom informacijom. Rezultat simulacije je prikazan grafički u vidu verovatnoće greške po simbolu (eng. SER - Symbol Error Rate) u odnosu na signal/šum (eng. SNR - Signal-To-Noice), kao i verovatnoće greške po bitu (eng. BER - Bit Error Rate) u odnosu na SNR, koji obezbeđuje informacije o performansi sistema. Ovaj rad je prirodni nastavak rada (Mladenovic et al, 2010). Sa druge strane potrošnja energije pri prenosu informacija može imati značajnu ulogu u dužem vremenskom periodu. U pokušaju da se smanji potrošnja ulazi se u domen razmatranja njene optimalne iskorišćenosti za iste ili približno iste efekte prenosa informacije, što se naziva energetska efikasnost.

Ovaj rad je organizovan na sledeći način. U sekciji 2 daje se opis modela, načini i postupci korišćenja CAS i simboličke obrade. Sekcija 3 daje detaljnu analizu OFDM DVB prijemnika upotrebom navedenog pristupa. U sekcija 4 prikazana je zavisnost energetske efikasnosti u odnosu na energiju po bitu i energiju po simbolu. Zaključak je pokazan u sekciji 5.

\section{METODE SIMBOLIČKE OBRADE}

Vrednost simboličke obrade je poznata i u industriji i u akademskim krugovima. U industriji ona je korišćena kao pomoć u dizajnu sistema i elektronskih kola. U akademskim institucijama, korišćena je kao pomoćni alat u nastavi. Pišući simulacioni kôd za simboličku obradu mogu se izvoditi matematičke operacije bez grešaka, čak i da se pronađu grešaka u ručnom izvođenju objavljenih rezultata (Mladenovic et al, 2014). Takođe, simbolička obrada se može koristiti za pronalaženje izraza u zatvorenom obliku, i prilikom izračunavanja velikog broja iteracija; ili izvođenje funkcije greške usled konačne dužine reči u zapisu (Lutovac et al, 2013), Stoga, simbolička obrada može pomoći da se steknu uvid u to kako sistem radi, a još više može se koristiti u praksi jer numerički alati mogu imati problema sa tačnošću i značajno povećati složenost. Ona određuje neslaganje između teorijskih performansi i numeričkih simulacija

Simbolička obrada radi sa simbolima. Svaki simbol može biti zamenjen brojem kad simbolički izrazi postanu nepraktično, na primer, za crtanje odziva na određenu pobudu. Stoga, pisanje programa koji koriste simboličku obradu može izgledati kao skup instrukcija koje manipulišu simbolima i mogu da se koriste za obavljanje mnogo šireg spektra aktivnosti. Efikasnost simboličke obrade postaje važnija ako su sistemi i signali složeniji (Proakis \& Salehi, 2000).

Ako ne postoji algebarsko rešenje za neki oblike obrade, i simbolička obrada neće biti u stanju da reši neki problem. Čak i tada, krajnji rezultat može biti izražen u vidu specijalne funkcije koja se može izračunati za poznate numeričke vrednosti parametara sistema. Neke metode u kojima je pogodno koristiti simboličku obradu su: izračunavanje frekvencijskog odziva, parametarske iteracije, optimizacija u dizajniranju filtra, itd.

\section{OFDM PRIJEMNIK - SIMULACIONI MODEL}

Kompletni OFDM DVB predajnik je simuliran primenom CAS u radu (Mladenovic et al, 2010). Parametri koji se koriste za simulaciju, uzeti su iz rada (Acosta, 2008). Dakle, vrednost $T_{U}=224 \cdot 10^{-6}$ uzima se za period korisnog OFDM simbola, osnovna perioda je $T=T_{U} / 2048$, parametar $G$ može biti biran za vrednosti 1/4, 1/8, 1/16 i 1/32, dajući trajanje zaštitnog intervala delta $=G \cdot T_{U}$. U ovom slučaju, ukupan period OFDM simbola je $T_{S}=T_{U}+$ delta. Ukupan broj podnosilaca je $K_{\max }=$ 1705, a dužina IFFT/FFT je $F_{S}=4096$. Noseća frekvencija je približno $90 \mathrm{MHz}$, što je u opsegu petog VHF TV kanala u bilo kom gradu. Odgovarajući simulacioni period $T$ se definiše kao osnovni period propusnog opsega, a to se odnosi na vremenski period $1 / R_{s}$. Ostali parametri za potrebe simulacije su perioda osnovnog nosioca $q=10$ i noseća frekvencija je $f_{c}=q \cdot(1 / T)$. Simulacioni model je zasnovan na OFDM DVB signalima po standardima za Evropske zemaljske digitalne televizijske servise i proceduri korak-po-korak koja prati Matlab kôd opisan u radu (Acosta, 2008).

Sa druge strane, koristeći SchematicSolver možemo nacrtati blok dijagrame koji predstavljaju različite sisteme. Njena paleta obezbeđuje grafički korisnički interfejs za konstruisanje modela kao blok dijagrami korišćenjem miša za obavljanje zadataka crtanja. Prema tome, implementacioni kôd se generiše u pozadini i vidljiv je za korisnika. SchematicSolver opisuje sistem kao listu elemenata koja sadrži sve detalje za crtanje, rešavanje, simuliranje i implementaciju sistema. Slika 1. prikazuje blok

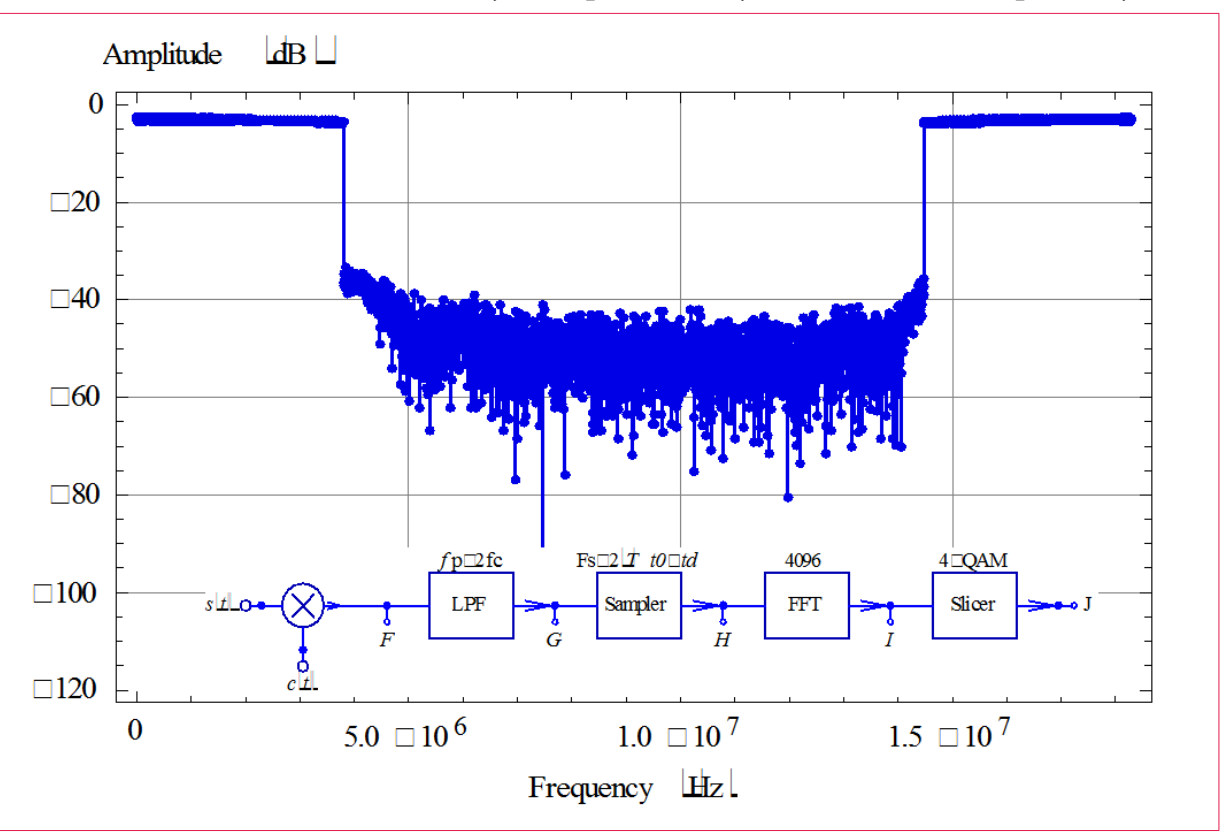

Sl. 1 Blok dijagram OFDM DVB prijemnika i frekventni odziv 
dijagram OFDM DVB prijemnika nacrtanog korišćenjem SchematicSolver i njegov frekventni odziv.

\section{A. Prijemni signal}

U radu (Acosta, 2008) nije razmatrana analiza sistema u prisustvu AWGN, samo zakašnjenja koje nastaje kao posledica širenja signala koje nastaje kao posledica širenja signala (Bank et al, 2010). U ovom radu, AWGN se dodaje u kanal i posmatra se simbolički simulacioni model od početka do kraja.
$\mathrm{Na}$ početku je potrebno generisati neke važne parametre. Oznaka uoft se odnosi na signal koji se šalje iz OFDM DVB predajnika (Acosta, 2008), što je označeno sa $s(t)$ u blok dijagramu. Signal $s(t)$ prolazi kroz AWGN kanal gde su prisutni šum i kašnjenje označeni sa $n$ i delay na prijemu, respektivno. Prema (Acosta, 2008) usvoja se da je delay $=64$. Na slici 2 pokazan je prijemni signal u prisustvu AWGN sa kašnjenjem pre procesa demodulaciju. Prijemni signal sa kašnjenjem i AWGN obeleženi su kao rxSER.

$$
\operatorname{rXSER}=\operatorname{Table}\left[\text { uoft }[[; ;]]+10^{-\frac{\text { EsNOdB }[i i]]}{20}} * \mathrm{n}[[; ;]],\{i i, \text { Length }[\text { ESNOdB }]\}\right]
$$

gde je šum predstavljen na sledeći način

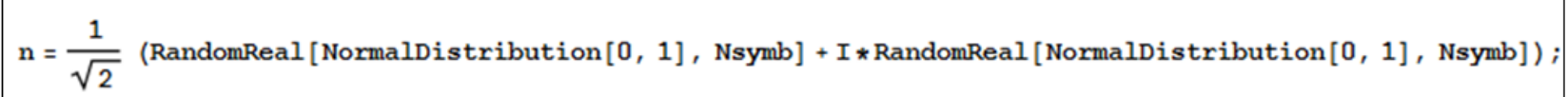

Oznaka [[;;]] znači da su svi simboli uključeni u obradu. EsN0dB je definisanu u odeljku D ove sekcije. Broj nivoa za QPSK je numLevel $=4$, a Nsymb pokazuje broj simbola.

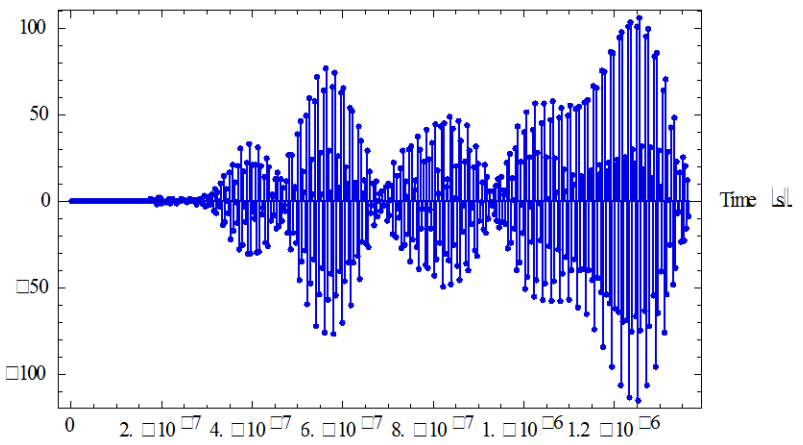

Sl. 2 Prijemni signal $s(t)$ u prisustvu AWGN i kašnjenja

Sledeći korak je uvođenje kašnjanja u signal gde se dobija novi signal obeležen uoftnew:

uoftnew=PadLeft [rxSER [ [1] ] [;;] ] // SequenceToList, Length[s]+delay] // ListToSequence

Instrukcija ListToSequence konvertuje listu uzoraka u niz (sekvencu), a SequenceToList radi suprotnu operaciju. Nakon uvođenja simboličkog kôda prati proces demodulacija signala i oblici signala su prikazani na Slici 3 i 4.

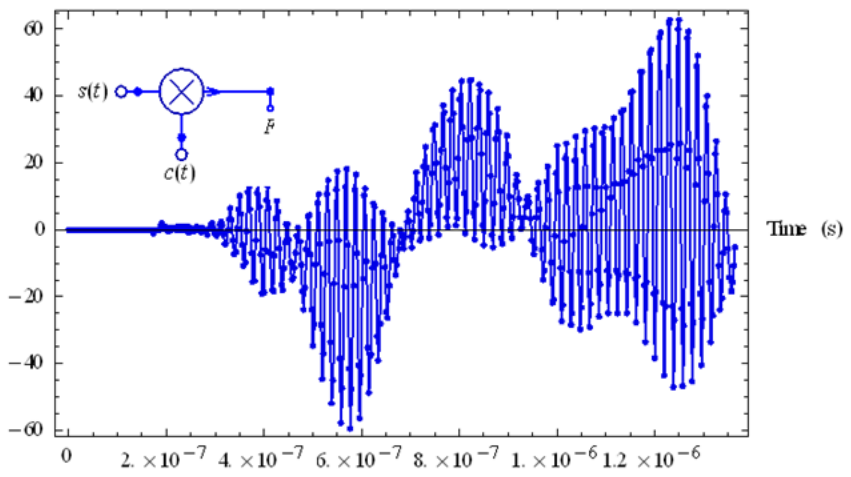

Sl. 3 Realni deo prijemnog signala nakon konverzije na dole $\mathrm{u}$ tački (F)

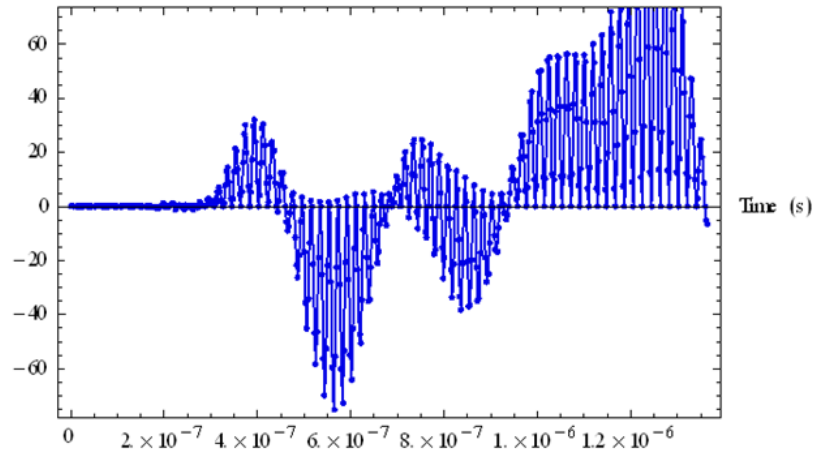

Sl. 4 Imaginarni deo prijemnog signala nakon konverzije na dole u tački (F) 
Generisani kôd za prijemni signal u tački (F) je:

$s=\operatorname{Re}[$ ListToSequence [SequenceToList [uoftnew [ [1; iLength [uoftnew] ] ] * ã^(I 2.p

fc Table $[i,\{i, 0$, Length [uoftnew]-1\}])]];

Na slici 5 je prikazan frekventni odziv i propusni opseg jednog kanala u tački (F) obeležen kao r_tilde.

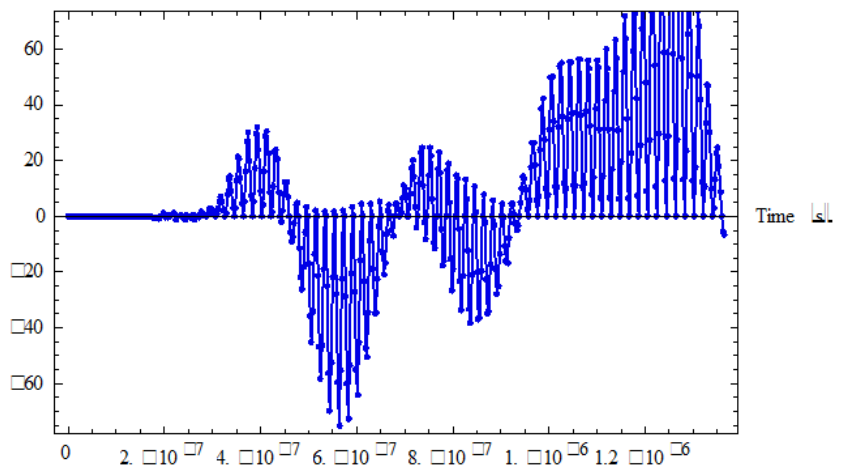

Sl. 5 Frekventni odziv signala r_tilde u tački (F)

\section{B. Generisanje obrađenog signala}

U radu (Acosta, 2008), predložen je Butterworthov filter $13^{\text {og }}$ reda sa graničnom frekvencijom od $1 / T$, a isti filter je realizovan pomoću SchematicSolvera u radu (Mladenovic et al, 2010). Spomenuti filter je isti i kod predajnika i kod prijemnika. Butterworthove filtere karakteriše amplitudni odziv koji ima maksimalno ravan odziv amplitude u propusnom opsegu. Amplitudni odziv je prikazan u radu (Mladenovic et al, 2010). Na slikama 6 i 7 pokazani su vremenski odzivi signala r_info u fazi i u kvadraturi posle filtriranja u tački (G). SchematicSolver pruža generisanje procesa filtriranja koristeći

$\{r$ InfoRe, rInfoFinalR $\}=$ DiscreteSystemImplementationProcessing [rTildeRe,

initialConditions, systemParameters, procedureName];

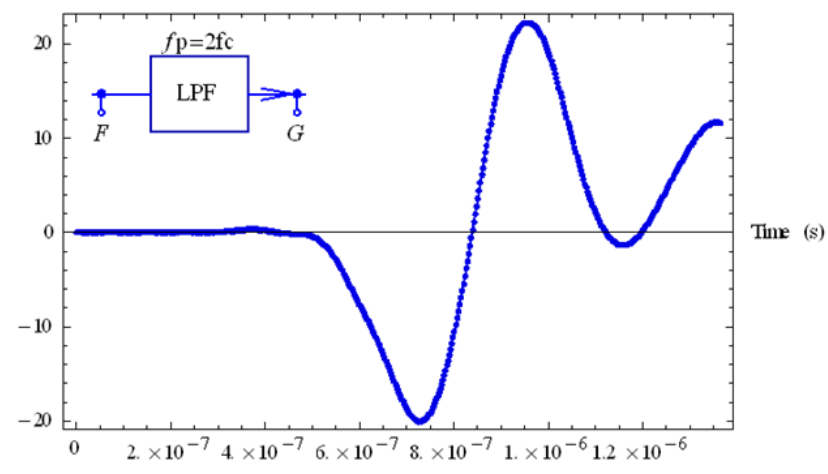

Sl. 6 Vremenski odziv u fazi $(\mathrm{G})$

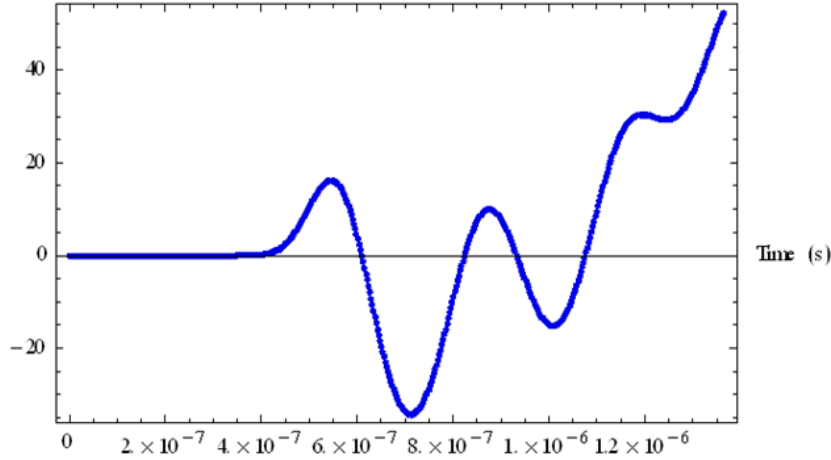

Sl. 7 Vremenski odziv u kvadraturi $(\mathrm{G})$

Sledeći blok je kolo za odmeravanje i njegov odziv signala je prikazan na slici 8 .

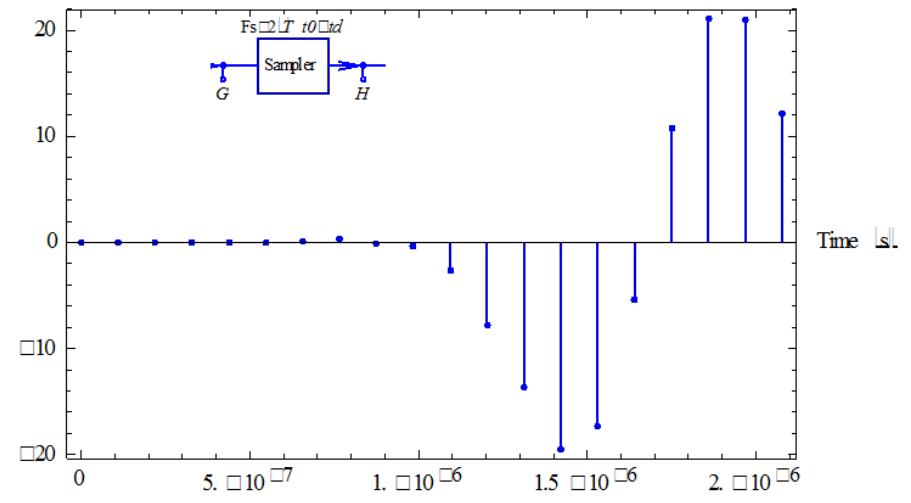

Sl. 8 Posle odmeravanja vremenski odziv signala r_data u $(\mathrm{H})$ 


\section{QPSK konstelacija i post procesiranje}

FFT bloka sledi posle niskopropusnog filtriranje i uzorkovanja primljenog OFDM signala. Izlaz FFT modulacije bloka dobija se konstelacioni dijagram. Ovo prolazi kroz QPSK slajser, koji dodeljuje primljene simbole u četiri moguće konstelacione tačke. U idealnom slučaju simboli su označeni kao alphabet=\{-1-I,-1+I,1-I,1+I\}. Greška, koja je greška simbola i označen kao inf, izračunava se upoređivanjem originalne konstelacije sa jednom dobijenom iz QPSK slajsera. Originalni konstelacioni dijagram je prikazan na slici 9, dok je konstelacija na prijemu prikazana na slici 10, i implementacioni kôd je napisan na sledeći način:

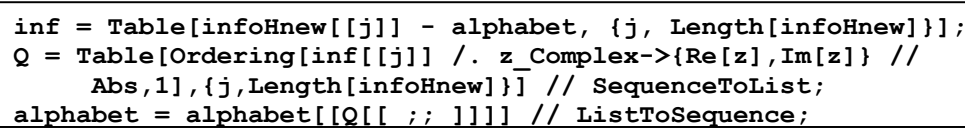

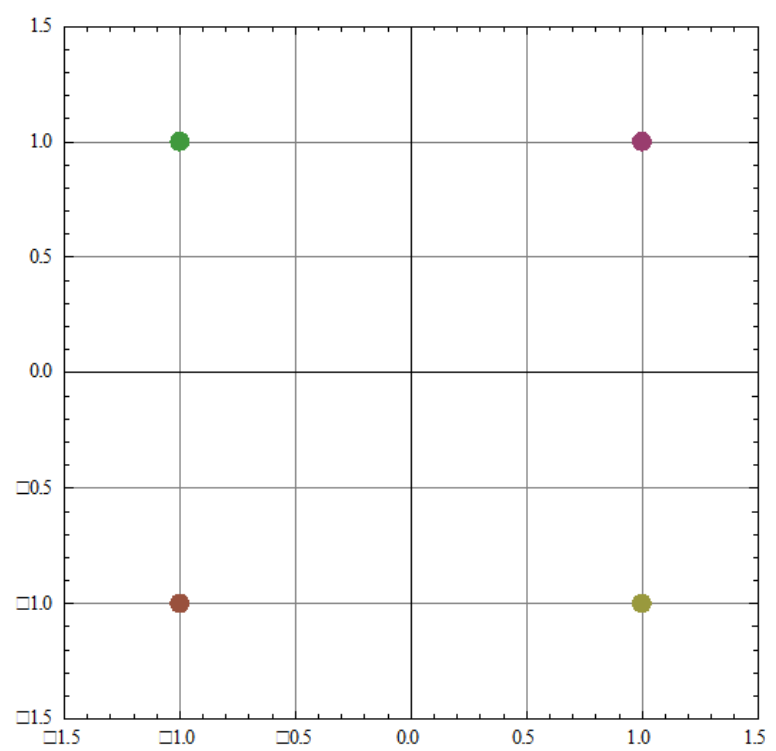

Sl. 9 Originalni konstelacioni dijagram QPSK signala bez AWGN i kašnjenja

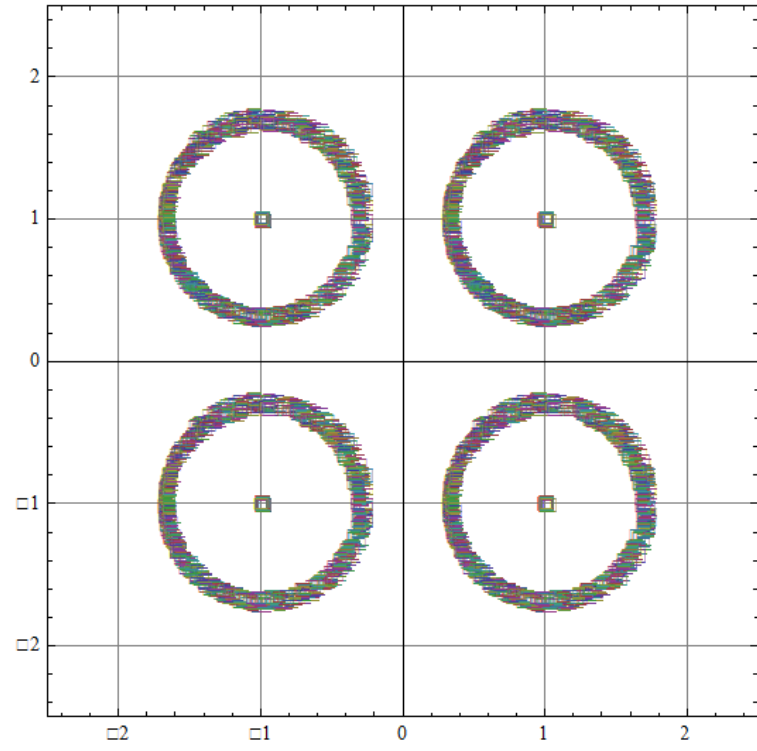

Sl. 10 Originalni konstelacioni dijagram QPSK signala sa AWGN i kašnjenjem

U fazi post procesiranja, u ovom radu se izračunava poluprečnik kruga detekcije greške usled šuma i kašnjenja. Pošto su sva četiri kruga identična u oblasti detekcije, računa se poluprečnik samo jednog kruga. Prvo se eliminiše detektovani signal u centru kruga (u tačkama alphabet $=\{-1-I,-1+I, 1-I, 1+I\})$.

$$
\begin{aligned}
& \mathrm{a}=\sqrt{(\operatorname{infRe}[[\mathrm{x} 1]]-\operatorname{infRe}[[\mathrm{x} 2]])^{2}+(\operatorname{infIm}[[\mathrm{x} 1]]-\operatorname{infIm}[[\mathrm{x} 2]])^{2}} ; \\
& \mathrm{b}=\sqrt{(\operatorname{infRe}[[\mathrm{x} 1]]-\operatorname{infRe}[[\mathrm{x} 3]])^{2}+(\operatorname{infIm}[[\mathrm{x} 1]]-\operatorname{infIm}[[\mathrm{x} 3]])^{2}} ; \\
& \mathrm{c}=\sqrt{(\operatorname{infRe}[[\mathrm{x} 2]]-\operatorname{infRe}[[\mathrm{x} 3]])^{2}+(\operatorname{infIm}[[\mathrm{x} 2]]-\operatorname{infIm}[[\mathrm{x} 3]])^{2}} ;
\end{aligned}
$$

gde su a, b, c dužine stranica proizvoljnog trougla, a x1, x2 i x3 proizvoljni indeksi pogrešno detektovanih tačaka na krugu. Korišćenjem Heronove formule i formule za izračunavanje poluprečnika moguće je pisati:

$$
\mathrm{S}=\frac{\mathrm{a}+\mathrm{b}+\mathrm{c}}{2} ; \mathrm{R}=\frac{\mathrm{a} * \mathrm{~b} * \mathrm{C}}{4 * \sqrt{\mathrm{S}(\mathrm{S}-\mathrm{a}) *(\mathrm{~S}-\mathrm{b}) *(\mathrm{~S}-\mathrm{c})}}
$$

gde je S poluobim trougla, a R poluprečnik.

\section{Dobijanje BER i SER post procesiranjem}

Post processing se koristi u obradi signala upotrebom dodatnog softvera na takav način da se pronađu rezultati koji ne mogu biti izvedeni od strane prethodnog softvera. SchematicSolver opisuje sistem kao simbolički objekat u obliku liste elemenata. Postoje dva različita načina za predstavljanje: grafičko prezentovanje blok dijagrama, i tekstualni opis na blok-dijagrama. Simbolička obrada se može izvesti kao automatsko generisanje kôda koji implementira sistem, izračunava ulaznu sekvencu čiji elementi mogu biti simboli ili brojevi, i obrađuju ulaznu sekvencu sa kôdom koji je isti za simulaciju i implementaciju.
Teorijski verovatnoća greške simbola za pravougaonu QAM konstelaciju je data u radu [20] i to:

$$
P_{M}=1-\left(1-P_{\sqrt{M}}\right)^{2}
$$

gde je

$$
P_{\sqrt{M}}=2\left(1-\frac{1}{\sqrt{M}}\right) \cdot Q\left(\sqrt{\frac{3 \cdot E}{(M-1) \cdot N_{0}}}\right)
$$

i Q-funkcija; $\mathrm{M}=2 \mathrm{k}$ predstavlja broj nivoa i $\mathrm{k}$ broj bitova po simbolu. Rezultat simulacije je prikazan na slici 11 i slici 12 . Za analizu post procesiranja Es/N0 pripada opsegu od $\mathrm{z} 1=-3 \mathrm{~dB}$ do $\mathrm{z} 2=20 \mathrm{~dB}, \mathrm{tj}$. EsN0dB=Range[ $\mathrm{z} 1, \mathrm{z} 2]$. Relacija koja povezuje prosečnu energiju po bitu i prosečnu energiju po simbolu opisana je preko kôda EbN0dB=Log[2,numLevel ${ }^{\star}$ EsN0dB. 
Generisani signal sa AWGN definisan je

$\operatorname{rxSER}=\operatorname{Table}\left[\right.$ uoft $[[; ;]]+10^{-\frac{\text { EsNodB }[\text { iil] }}{20}} * \mathrm{n}[[; ;]],\{i i, \operatorname{Length}[$ ESNOdB $\left.]\}\right] ;$
$\operatorname{rxNoiseSER}=\operatorname{Sign}[\operatorname{Re}[\operatorname{rXSER}]]+\mathrm{I} * \operatorname{Sign}[\operatorname{Im}[\operatorname{rXSER}]]$

Razlika između originalnog signala i signala sa smetnjom, daje vektor sa sa pogrešnim bitovima na mestima gde je nastala pogrešna detekcija, i to je opisano na sledeći način

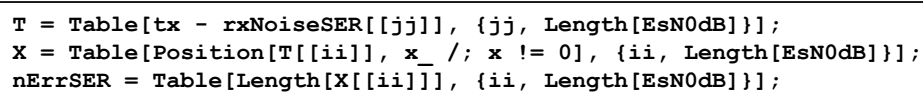

Simulacija pogrešnih simbola QPSK signala opisuje se preko kôda:

simSerQPSK $=$ nErrSER $[[;]] /$ Nsymb ;

Teorijski model izračunavanja SER opisan je na simbolički način:

$$
\text { theorySerQPSKdef }=\operatorname{ErfC}\left[\sqrt{\frac{1}{2} *\left(10^{\frac{\operatorname{EsNOdB}}{10}}\right)}\right]-\frac{1}{4} *\left(\operatorname{Erfc}\left[\sqrt{\frac{1}{2} *\left(10^{\frac{\text { EsNOdB }}{10}}\right)}\right]\right)^{2}
$$

Upotrebom naredbe ListLogPlot dobija se

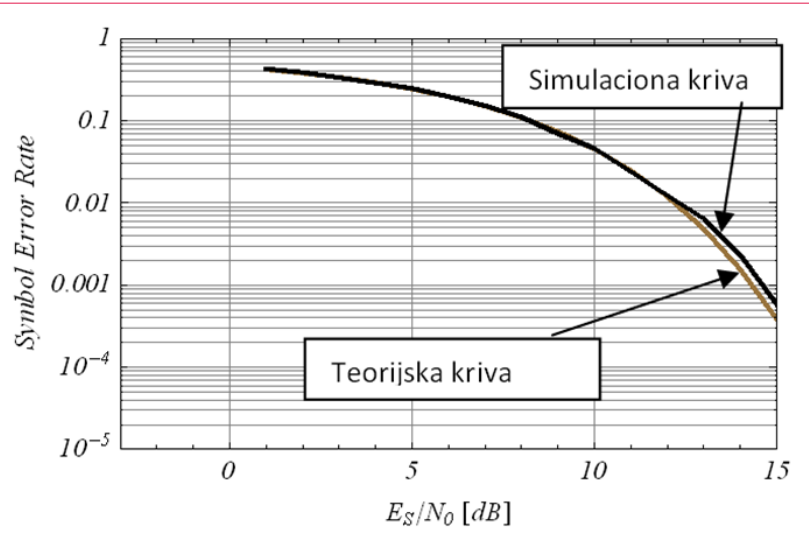

Sl. 11 Verovatnoće greške po simbolu u odnosu na SNR kod QPSK

Analiza BER je ista, osim što se uzima vrednost EbN0dB umesto EsN0dB. Lako je primetiti da su teorijski kriva i dobijena simbolična kriva gotovo iste.

\section{ENERGETSKA EFIKASNOST OFDM PRIJEMNIKA}

U poslednjoj deceniji u informacionim tehnologijama energetska efikasnost počinje da zauzima važno mesto kao bitan parametar u proceni potrošnje energije u nekom sistemu (Feng, 2013). Međutim, razni su pristupi u definicijama energetske efikasnosti i oni uglavnom zavise od oblasti u kojima se vrši procena i izračunavanje ovog bitnog parametra sa aspekta uštede energije (Digital Communications KTN, 2009). Tako i u ovom slučaju, mi ćemo posmatrati nekoliko aspekata energetske efikasnosti u definisati je u skladu sa parametrima sistema koji su dostupni i bitni za prenos informacija. Energetska efikasnost se definiše kao odnos ukupnog protoka informacija po svim nosiocima i ukupne energije po simbolu ili bitu, tj. energetska efikasnost je broj prenesenih simbola/ bitova po Džulu (Huan et al, 2013). U ovom slučaju energetska efikasnost se računa u odnosu na ukupnu energiju koja je utrošena za prenos svih bitova u jednom trenutku.

U sekciji 3, podsekcija D, definisani su opsezi vrednosti EsNOdB i veza između njih. U skladu sa tim vrednostima izračunavamo energiju po simbolu (Huan et al, 2013):

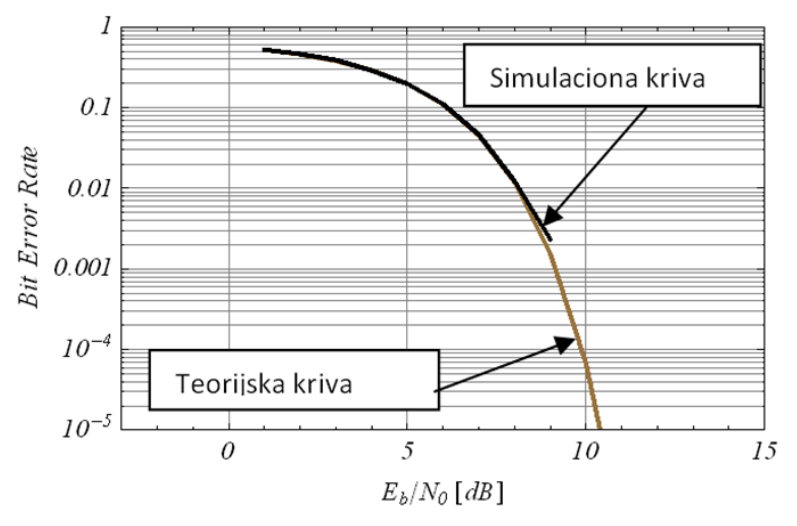

Sl. 12 Verovatnoće greške po bitu u odnosu na SNR kod QPSK

EnergijaPoSimbolu $=10^{\wedge}($ EsN0dB/10); i energiju po bitu: EnergijaPoBitu $=10^{\wedge}(\mathrm{EbN} 0 \mathrm{~dB} / 10)$. Iz toga sledi da je protok izražen preko simbola: $r E s=W /\left(2^{\star} M\right)^{\star} \log [2$, EnergijaPoSimbolu] i protok izražen preko bitova: $r E b=W /$ $\left(2^{\star} \mathrm{M}\right)^{\star} \log [2$,EnergijaPoBitu], gde su $\mathrm{W}=2 / \mathrm{T}$ propusni opseg $\mathrm{i}$ $\mathrm{M}$ je broj nivoa simbola. Energetska efikasnost izražena preko odnosa ukupne energije koja je utrošena za prenos svih simbola u jednom trenutku iznosi Uees=rEs/ (EnergijaPoSimbolu // Total) i preko svih bitova Ueeb=rEb/ (EnergijaPoBitu // Total). Ukupan protok se dobija množenjem protoka po nosiocu sa ukupnim brojem nosilaca.

Na slikama 13 i 14 prikazane su promene energetske efikasnosti u zavisnosti od protoka po simbolu pri konstantnoj ukupnoj energiji koja se ulaže za slanje simbola, i promena energetske efikasnosti u funkciji promene ukupne energije za slanje simbola pri konstantnom protoku u simboli.

Povećanjem protoka u simbolima povećava se energetska efikasnost pri konstantnoj ukupnoj energiji po simbolu, dok se u drugom slučaju povećanjem energije po simbolu smanjuje energetska efikasnost pri konstantnom protoku u simbolima.

Na slikama 15 i 16 prikazane su promene energetske efikasnosti u zavisnosti od protoka po bitu pri konstantnoj ukupnoj energiji koja se ulaže za slanje bitova, i promena energetske efikasnosti u funkciji promene ukupne energije za slanje bitova pri konstantnom protoku u bitovima. 
Energetska efikasnost OFDM sistema u odnosu na energiju po simboh

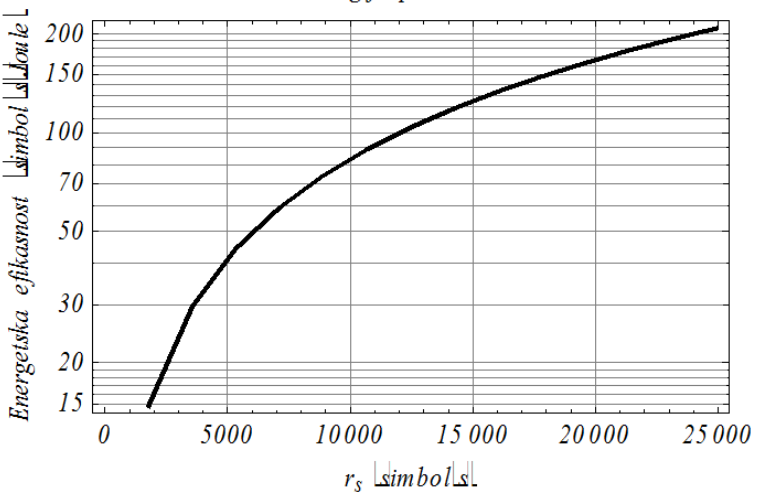

S1. 13 Energetska efikasnost OFDM sistema u odnosu na energiju po simbolu

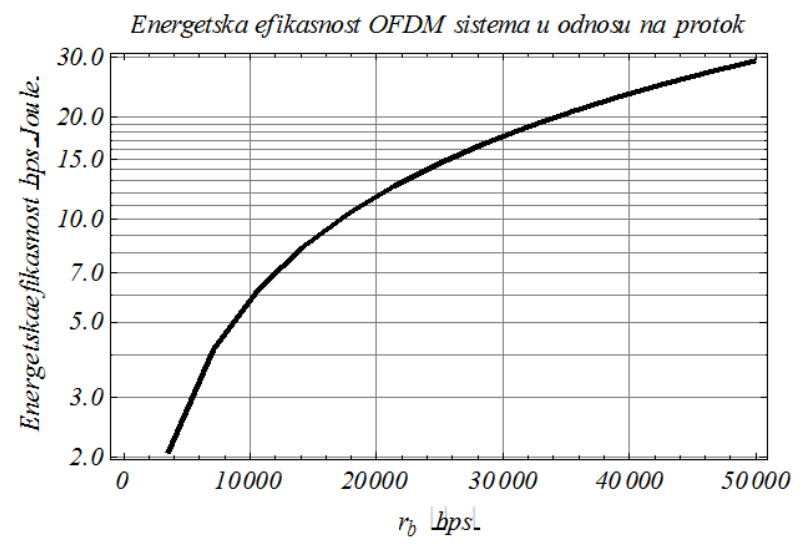

S1. 15 Energetska efikasnost OFDM sistema u odnosu na protok

Sa slika se vidi da se povećanjem protoka u bitovima povećava energetska efikasnost pri konstantnoj ukupnoj energiji po bitu, i povećanjem povećanjem energije po bitu smanjuje energetska efikasnost.

\section{REZIME}

Algebarski računarski sistemi, simbolička obrada i post procesiranje su korišćeni za simulaciju OFDM DVB prijemnika. Uprkos činjenici da su numerički alati danas u široj upotrebi i imaju veliku zastupljenost u analizi i simulaciji u inženjerskim oblastima, simbolički pristup menja tačku gledišta i obezbeđuje elemente analize, simulacije i obrade koje trenutno ne postoje $\mathrm{u}$ numeričkim analizama. Samo neke od pogodnosti su opisane u ovom radu i to: vizionarski koncept naprednog računanja, potpuno integrisano matematičko okruženje, simbolički jezik, simbolički računarski jezik, razne računarske programske paradigme i kratak ciklus razvoja softvera. Na takav način, algebarski računarski sistemi i simbolička obrada otvara mnoge mogućnosti širenja novih ideja i promena konceptualnog dizajna koje je trenutno prisutno u oblasti elektrotehnike uopšte. Takođe, sve značajnu ulogu će imati i koncept energetske efikasnosti koji će morati da obezbedi racionalniju i optimizovaniju potrošnju energije u oblasti potrošnje električne energije.

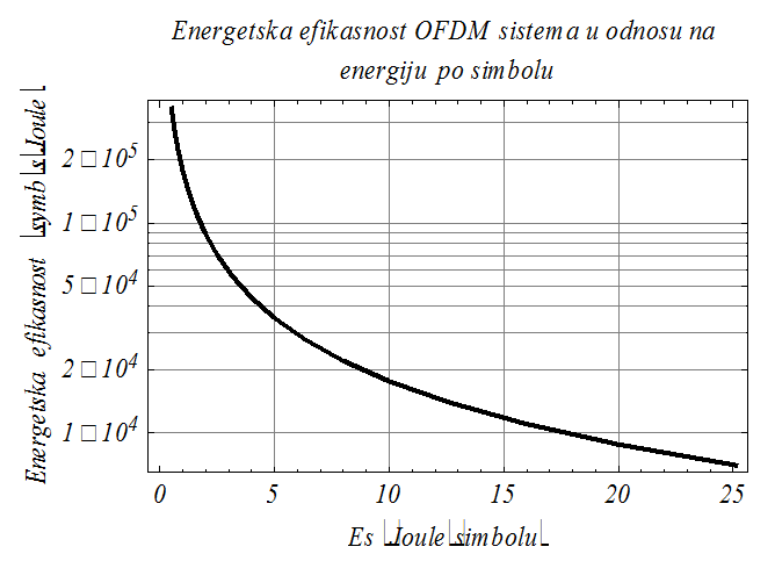

Sl. 14 Energetska efikasnost OFDM sistema u odnosu na energiju po simbolu

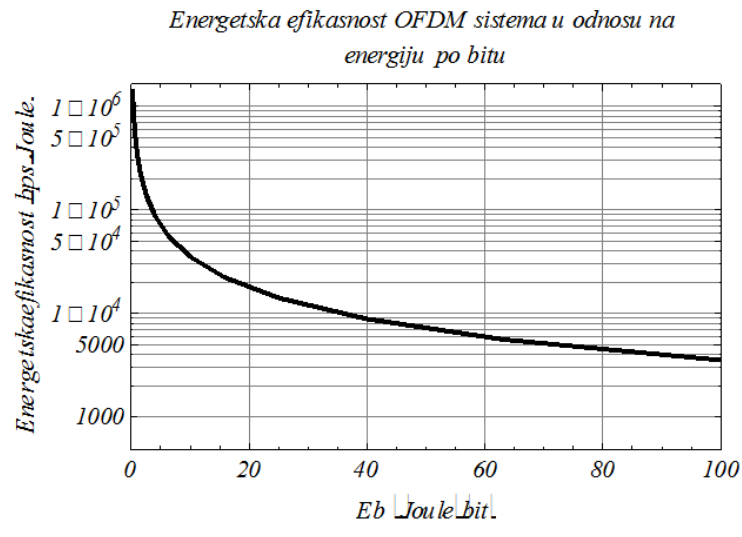

Sl. 16 Energetska efikasnost OFDM sistema u odnosu na energiju po bitu

\section{LITERATURA}

Acosta, G. (2001). OFDM Simulation Using Matlab, Smart Antenna Research Laboratory. Retrieved May 20, 2003, from http://www.ece.gatech.edu/research/labs/sarl/ tutorials/ OFDM/Tutorial_web.pdf

Bank, M., Bank, M., Hilp, B., \& Mahlab, U. (2010). OFDMA Systems, Pilot Signals and Doppler Effect. The IUP Journal of Telecommunicationc, 2(2), 7-13.

Broadcast papers. (2003). Retrieved May 9, 2003, from http:// www.broadcastpapers.com/tvtran/ HarrisDVBTDeliverMobRec01.htm http://www.broadcastpapers.com/tvtran/ ITISMagicsOfDTV10.htm

DVB-T standard. (2003). Retrieved May 20, 2003, from http:// www.kjmbc.co.kr/old/beta/ofdm/ofdm.html

Feng, D., Jiang, C., Lim, G., Cimini, L.J., Feng, G., \& Ye Li, G. (2013). A Survey of Energy-Efficient Wireless, IEEE COMMUNICATIONS SURVEYS \& TUTORIALS, 15(1), FIRST QUARTER 2013.

Fischer, W. (2010). Digital Video and Audio Broadcasting Technology, Signals and Communication Technology. Berlin: Springer-Verlag Heidelberg.

Gielen, G., \& Sansen, W. (1991). Symbolic analysis of automated design of analog integrated circuits. Norwell, MA: Kluwer Academic Publishers. 
Glover, I., \& Grant, P. (2010). Digital Communications. New York: Pearson Education.

Huan, Y., HaoHao, Q., YunZhou,L., YiFei, Z., XiBin, X., \& Jing, W. (2013). Energy-efficient power allocation for non-regenerative OFDM relay links, SCIENCE CHINA Information Sciences. DOI: 10.1007/s11432-012-4770-9

Lutovac, M., \& Mladenovic, V. (2007). Development of aeronautical communication system using computer algebra systems, in Proc. XXV Simposium - PosTel 2007, Belgrade, December 2007.

Lutovac, M., \& Tosic, D. (2006). Symbolic analysis and design of control systems using Mathematica, International Journal of Control, Special Issue on Symbolic Computing in Control, 79 (11), 1368-1381.

Lutovac, M., \& Tosic, D. (2010). SchematicSolver Version 2.2, 2010. Retrieved May 20, 2003, from http://books.google. com/books?id=9ue-uVG_JsC

Lutovac, M., Certic, J., \& Milic, L. (2010). Digital Filter Design Using Computer Algebra Systems, Circuits Syst Signal Process, 29(1), 51-64.

Lutovac, M., Mladenovic, V., \& Lutovac, M. (2013). Development of Aeronautical Communication System for Air Traffic Control Using OFDM and Computer Algebra Systems, SIC, 22(2). Retrieved May 20, 2003, from http://sic.ici.ro/ sic2013_2/index.html

Lutovac, M., Tosic, M., \& Evans, B. (2001). Filter Design for Signal Processing using MATLAB and Mathematica. Upper Saddle River, NJ: Prentice Hall.

MathWorks. (2005). MATLAB. Retrieved May 20, 2003, from http://www.mathworks.com/
Mladenovic, V., Lutovac, M., \& Porrat, D. (2014). Symbolic Analysis as Universal Tool for Deriving Properties of Non-linear Algorithms-Case study of EM Algorithm K. Acta Polytechnica Hungarica, 11(2), 117-136.

Mladenovic, V., Porrat, D., \& Lutovac, M. (2010). Simulation of OFDM Transmitters and Post Processing with SchematicSolver and Mathematica as a Computer Algebra System, 5th (ECCSC'10), November 23-25, 2010, Belgrade, Serbia, pp. 278-281.

Nee, R., \& Prasad, R. (2000). OFDM Wireless Multimedia Communications. Norwood, MA: Artech House.

Porrat, D. (2007). Information Theory of Wideband Communications, IEEE Communications Surveys and Tutorials, 9(2), $2-16$.

Proakis, J., \& Salehi, M. (2000). Contemporary Communications Systems using MATLAB. CA: Brooks/Cole.

Schulze, H., \& Luders, C. (2005). Theory and Applications of OFDM and CDMA - Wideband Wireless Communications, West Sussex: John Wiley \& Sons.

The Digital Communications Knowledge Transfer Network. (2009). DCKTN Wireless Technology \& Spectrum Working Group. Retrieved May 20, 2003, from https://connect. innovateuk.org/documents/2849135/3712563/Optimisin g+use+of+Mobile+Radio+Spectrum.pdf/24c04e5d-7656463b-bcfd-b7b06a1ce062

Tosic, D., \& Lutovac, M. (2007). Advances in symbolic simulation of systems. The IPSI BgD Transactions on Advanced Research, 3(1), Jan. 2007.

Wolfram, S. (2003). The Mathematica book, Cambridge: Cambridge University press. 